\title{
p38 MAPK signaling acts upstream of LIF-dependent neuroprotection during photoreceptor degeneration
}

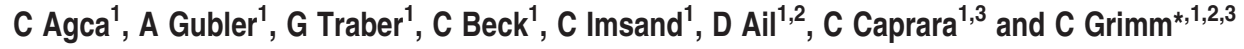

In many blinding diseases of the retina, loss of function and thus severe visual impairment results from apoptotic cell death of damaged photoreceptors. In an attempt to survive, injured photoreceptors generate survival signals to induce intercellular protective mechanisms that eventually may rescue photoreceptors from entering an apoptotic death pathway. One such endogenous survival pathway is controlled by leukemia inhibitory factor (LIF), which is produced by a subset of Muller glia cells in response to photoreceptor injury. In the absence of LIF, survival components are not activated and photoreceptor degeneration is accelerated. Although LIF is a crucial factor for photoreceptor survival, the detailed mechanism of its induction in the retina has not been elucidated. Here, we show that administration of tumor necrosis factor-alpha (TNF) was sufficient to fully upregulate Lif expression in Muller cells in vitro and the retina in vivo. Increased Lif expression depended on p38 mitogenactivated protein kinase (MAPK) since inhibition of its activity abolished Lif expression in vitro and in vivo. Inhibition of p38 MAPK activity reduced the Lif expression also in the model of light-induced retinal degeneration and resulted in increased cell death in the light-exposed retina. Thus, expression of Lif in the injured retina and activation of the endogenous survival pathway involve signaling through p38 MAPK.

Cell Death and Disease (2013) 4, e785; doi:10.1038/cddis.2013.323; published online 5 September 2013

Subject Category: Neuroscience

Throughout our life span, cells have to be repaired or regenerated in order to maintain tissue function. Whereas this happens frequently in most parts of the body, the regeneration capacity of the nervous system is generally very limited in mammals, and the consequences of neuronal disease or injury are mostly irreversible. Therefore, it is crucial to rescue neurons from devastating insults, a task that requires activation of endogenous neuroprotective systems. In the retina, several pathways exist to support the survival of neurons. ${ }^{1-7}$ Leukemia inhibitory factor (LIF) controls one of these pathways and is one of the most important endogenous factors for neuroprotection in the retina. ${ }^{1,2}$ Photoreceptor injury or degeneration activates a subset of Muller glia cells to express Lif, which controls a cascade of neuroprotective signaling between photoreceptors and Muller cells. ${ }^{1,8}$ These signaling events include activation of the Janus kinase/signal transducer and activator of transcription (JAK/STAT) pathway, ${ }^{9-11}$ and result in the upregulation of several genes important for neuroprotection, including signal transducer and activator of transcription-3 (Stat3), endothelin-2 (End2) and fibroblast growth factor-2 (Fgf2), and for gliosis (glial fibrillary acidic protein, Gfap). ${ }^{1,12}$ In the absence of LIF, none of these factors is induced, and photoreceptor cell death is accelerated. ${ }^{1,12}$
Although downstream events of LIF signaling have been studied in the retina, ${ }^{1,12-14}$ the signal that initiates Lif expression has not been elucidated. One of the hypotheses for the initiation of survival pathways is based on the generation of reactive oxygen species (ROS) in stressed photoreceptors. ${ }^{15-17}$ Subtoxic levels of ROS have been shown to be neuroprotective for photoreceptors and ROS may act as signaling molecules for survival pathways in the retina. ${ }^{15-18}$ Another hypothesis especially with respect to the involvement of Muller cells includes tumor necrosis factoralpha (TNF) signaling, as TNF has been recently shown to be the key signaling molecule for Muller cell proliferation and differentiation into a photoreceptor fate in the degenerating zebrafish retina. ${ }^{19}$ However, its role during photoreceptor degeneration in the mammalian retina has not been identified in detail.

TNF was shown to regulate expression of several important factors that mediate a proinflammatory response. Likewise, TNF treatment upregulates several cytokines including Lif in various cell types. ${ }^{20,21}$ The reported neuroprotective effect of TNF is mostly attributed to nuclear factor kappa-light-chainenhancer of activated $\mathrm{B}$ cells $(\mathrm{NF} \kappa \mathrm{B})$ activation and the resulting differential regulation of gene expression. ${ }^{22-27}$

\footnotetext{
${ }^{1}$ Lab for Retinal Cell Biology, Department of Ophthalmology, University of Zurich, Zurich 8091, Switzerland; ${ }^{2}$ Neuroscience Center (ZNZ), University of Zurich, Zurich 8091, Switzerland and ${ }^{3}$ Zurich Center for Integrative Human Physiology (ZIHP), University of Zurich, Zurich 8091, Switzerland

*Corresponding author: C Grimm, Department of Ophthalmology, University of Zurich, Lab for Retinal Cell Biology, Wagistrasse 14, Schlieren 8952, Switzerland. Tel: +41 44556 3001; Fax: +41 44556 3999; E-mail: cgrimm@opht.uzh.ch

Keywords: leukemia inhibitory factor (LIF); p38 MAPK; TNF; Muller glia cell; photoreceptor; neuroprotection

Abbreviations: BSA, bovine serum albumin; Clc, cardiotrophin-like cytokine; Cntf, ciliary neurotrophic factor; End2, endothelin-2; Fgf2, fibroblast growth factor-2; Gfap, glial fibrillary acidic protein; IL-6, interleukin-6; JAK/STAT, Janus kinase/signal transducer and activator of transcription; Lif, leukemia inhibitory factor; Lifr, leukemia inhibitory factor receptor; LIRD, light-induced retinal degeneration; MAPK, mitogen-activated protein kinase; NF $\kappa$ B, nuclear factor kappa-light-chain-enhancer of activated B cells; Pax6, paired box protein-6; RGC, retinal ganglion cell; rMC-1, rat Muller glia cell line-1; ROS, reactive oxygen species; SEM, standard error of the mean; Stat3, signal transducer and activator of transcription-3; TLR2, Toll-like receptor-2; TNF, tumor necrosis factor; Vim, vimentin

Received 10.6.13; revised 09.7.13; accepted 15.7.13; Edited by A Verkhratsky
} 
However, divergent data exist and various reports attribute TNF also a role in the promotion of neurodegeneration (reviewed in detail $^{22,23}$ ). Blocking TNF in a glaucoma model of retinal ganglion cell (RGC) death, for example, had beneficial effects on RGC survival. ${ }^{28-30}$ In contrast, increased survival of RGCs after axotomy of the optic nerve required elevated and not decreased TNF levels. ${ }^{31}$

In addition to $\mathrm{NF}_{\kappa} \mathrm{B}$, TNF has been shown to activate the p38 mitogen-activated protein kinase (MAPK) pathway in a variety of models, and a small number of genes have been identified that are regulated through p38 MAPK after TNF induction. ${ }^{27}$ However, similar to TNF, no consensus exists on the anti- or pro-apoptotic effects of p38 MAPK activity in neuronal tissues. Active p38 MAPK signaling has been shown to contribute to RGC death after ischemia or optic nerve axotomy. ${ }^{32,33}$ In contrast, recent findings suggest that p38 MAPK activity is important for RGC survival after ischemia/ reperfusion injury, ${ }^{34,35}$ and that active crosstalk between $\mathrm{NF}_{\kappa} \mathrm{B}$ and $\mathrm{p} 38 \mathrm{MAPK}$ pathways may be an important aspect of this neuroprotection. ${ }^{35}$

To date, the effects of TNF and p38 MAPK on photoreceptor protection and their possible role in the regulation of neuroprotective factors in the retina have not been studied. To gain insight into the mechanisms that regulate LIFmediated neuroprotection, we investigated the contributions of TNF and p38 MAPK to Lif expression both in vitro and in vivo, and tested the relevance of the findings in the model of light-induced retinal degeneration (LIRD) in vivo. The results show that p38 MAPK activity is neuroprotective and required to upregulate expression of Lif in the injured retina.

\section{Results}

TNF upregulates Lif expression through p38 MAPK in cultured Muller cells in vitro. Previously, it has been shown that treatment with recombinant TNF induces upregulation of Lif expression in fibroblasts and other cells. $^{20,21}$ Since LIF is crucial for endogenous neuroprotection in the retina and is expressed by a subset of Muller cells upon photoreceptor injury, we tested whether Muller cells upregulate Lif in response to TNF administration in vitro. When cultured rat Muller cells (rMC-1) ${ }^{36}$ were treated with TNF, Lif and Tnf were simultaneously upregulated 10.7- and 21-fold, respectively (Figure 1). This transcriptional response was fast and reached its peak at $1 \mathrm{~h}$ before it gradually decreased towards basal levels even though TNF was still present in the culture medium. This suggests a transcriptional induction by TNF followed by suppression of expression. The transient upregulation of Lif and Tnf in Muller cells is consistent with results from previously studied models. ${ }^{20,21}$ We also tested expression of genes that are known to be upregulated in activated Muller cells including Gfap, ciliary neurotrophic factor (Cntf) and Fgf2. ${ }^{1}$ However, none of these genes was activated by TNF demonstrating a specificity of TNF for the regulation of Lif expression in rMC-1 (Figure 1).

Stimulation of cells with TNF has been previously shown to induce p38 MAPK signaling. Thus, we determined the role of p38 MAPK in the regulation of Lif expression. Since the expression of Lif in cultured Muller cells was robust, we first

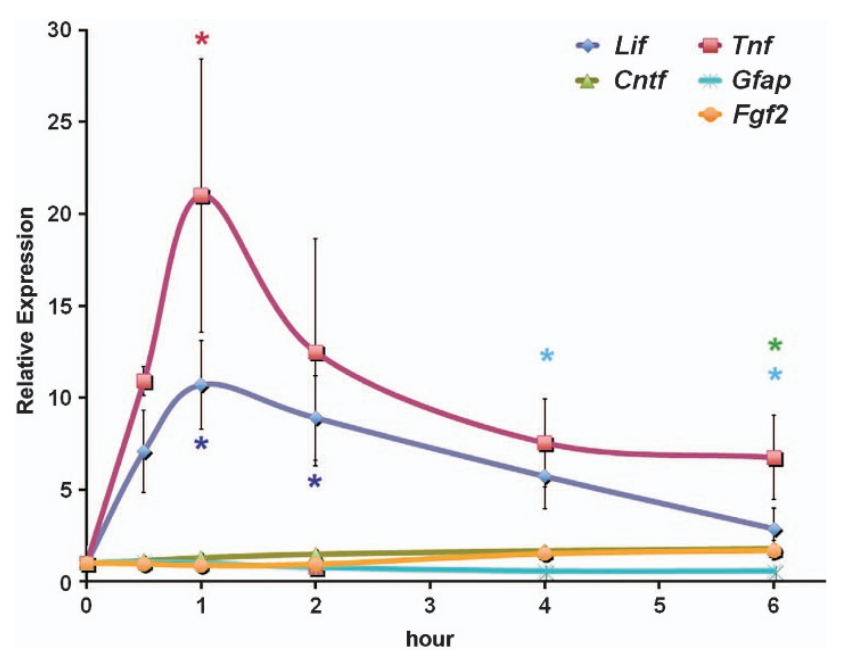

Figure 1 TNF treatment transiently upregulates Lif expression in Muller cells in vitro. Real-time PCR analysis of gene expression in $\mathrm{rMC}-1$ cells before $(0 \mathrm{~h})$ or at various timepoints during TNF treatment as indicated. TNF $(10 \mathrm{ng} / \mathrm{ml})$ treatment resulted in a strong upregulation of Lif expression as early as $30 \mathrm{~min}$. Peak of expression was at $1 \mathrm{~h}$. Tnf expression was upregulated similarly to Lif. In contrast, expression of Cntf, Gfap and Fgf2 was not affected by TNF. Shown are means \pm S.E.M. of $N=3$. ANOVA with Dunnett's post-tests was used to compare control levels (at ' 0 ') with expression levels of each gene at all timepoints after TNF treatment. Note that the color of the stars indicating significance match the color of the respective gene. ${ }^{\star} P<0.05$

tested the effect of p38 MAPK activity on basal Lif expression in the absence of TNF by using two specific chemical inhibitors for p38 MAPK activity, SB239063 and SB202190. ${ }^{37,38}$ Treatment with either SB compound downregulated $L$ if expression in a dose-dependent manner within $1 \mathrm{~h}$ of treatment and at a similar concentration range (Figures $2 \mathrm{a}$ and $\mathrm{b}$ ). As expected, inhibitor treatment did not block phosphorylation of p38 MAPK (see also Figures $5 \mathrm{~b}$ and c) but prevented its activity reducing activation of downstream targets like heat shock protein-27 (data not shown). The effect of p38 MAPK inhibition was specific for Lif as the expression of Gfap, Cntf and Fgf2 was not reduced (Figures 2a and b).

To analyze whether TNF-mediated upregulation of Lif expression also involves p38 MAPK signaling, we co-treated Muller cells with TNF and SB239063. Consistent with our results above (Figure 1), TNF treatment induced Lif expression (Figure 3a). However, inhibition of p38 MAPK activity by SB239063 completely blocked Lif upregulation in the presence of TNF (Figure 3a), suggesting that p38 MAPK activity is crucial not only for basal Lif expression but also for TNF-induced Lif upregulation.

Another signaling pathway known to be activated by TNF centers around $\mathrm{NF}_{\kappa} \mathrm{B}$. Since multiple potential binding sites for $\mathrm{NF}_{\kappa} \mathrm{B}$ are located in the Lif promoter region (not shown) and $\mathrm{NF}_{\kappa} \mathrm{B}$ was identified to bind the Lif promoter upon stimulation of cells with Toll-like receptor-2 (TLR2) agonists, ${ }^{39}$ we determined the activation of $\mathrm{NF}_{\kappa} \mathrm{B}$ in Muller cells upon TNF treatment using a luciferase reporter vector that contains $\mathrm{NF}_{\kappa} \mathrm{B}$ binding elements. Treatment with TNF strongly increased luciferase levels suggesting that $\mathrm{NF}_{\kappa} \mathrm{B}$ was activated in Muller cells under these conditions (Figure $3 b$ ). Importantly, addition of the p38 MAPK inhibitor SB202190 

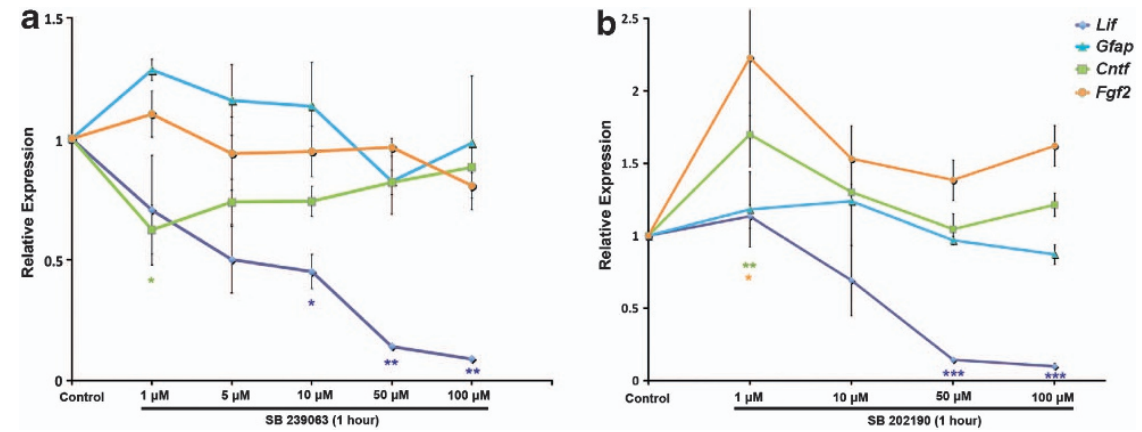

Figure 2 Inhibition of $\mathrm{p} 38$ MAPK activity downregulates Lif expression in Muller cells in vitro. Real-time PCR analysis of gene expression in rMC-1 cells before (control) or at $1 \mathrm{~h}$ of treatment with various concentrations (as indicated) of p38 MAPK inhibitors SB239063 (a) or SB202190 (b). Expression levels of Lif inversely correlated with the concentration of p38 MAPK inhibitors. Expression levels of Cntf, Gfap and Fgf2 were not affected. Shown are means \pm S.E.M. of $N=3$. ANOVA with Dunnett's post-tests was used to compare control levels with expression levels of each gene after inhibitor treatment. Note that the color of the stars indicating significance match the color of the respective gene. ${ }^{\star} P<0.05 ;{ }^{* \star} P<0.01 ;{ }^{* \star *} P<0.005$
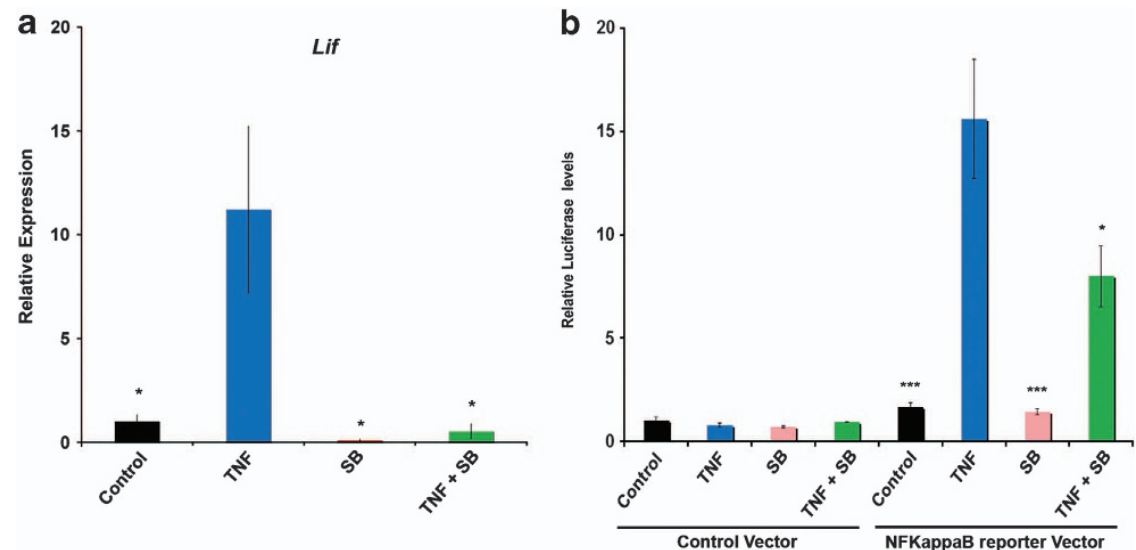

Figure 3 Inhibition of p38 MAPK activity prevents TNF-induced upregulation of Lif expression in Muller cells in vitro. (a) RT PCR analysis of Lif expression in rMC-1 cells before (control, black bar) or at $1 \mathrm{~h}$ of treatment with TNF (10 ng/ml, blue bar), p38 MAPK inhibitor SB239063 (SB, $100 \mu \mathrm{M}$, pink bar) or a combination of both (green bar). Inhibition of p38 MAPK activity downregulated basal Lif expression and blocked TNF-induced Lif upregulation. Shown are means \pm S.E.M. of $N=3$. ANOVA with Dunnett's post-tests was used to compare Liflevels after TNF injection with control levels or levels after SB or SB + TNF treatment. (b) Luciferase levels in rMC-1 cells transfected with a control vector or an NF $\kappa$ B reporter vector. Cells were treated for $6 \mathrm{~h}$ with TNF $(10 \mathrm{ng} / \mathrm{ml}$, blue bars), p38 MAPK inhibitor SB202190 (SB, $100 \mu \mathrm{M}$, pink bars), or a combination of both (green bars). Controls (black bars) were not treated. NF $\kappa$ B-mediated luciferase expression was upregulated by TNF treatment. The TNF-mediated upregulation was partially blocked by the inhibitor of p38 MAPK activity. ANOVA with Dunnett's post-tests was used to compare luciferase levels after TNF injection with levels of other treatments. Statistics were calculated seperately for the 'control vector' group and the 'NF $\kappa$ B vector' group. Shown are means \pm S.E.M. of $N=4$

completely inhibited TNF-induced Lif upregulation (Figure 3a), but reduced TNF-induced NF $\kappa$ B activity only by $49 \%$ leaving it still fivefold above control levels (Figure $3 b$ ). This indicates that, although p38 MAPK and NF $\kappa$ B pathways may interact, increased $\mathrm{NF} \kappa \mathrm{B}$ activity may not be sufficient to induce Lif expression in Muller cells in response to TNF treatment (Figure $3 b)$ in vitro.

Regulation of Lif expression in the neuronal retina in vivo. Our results show that TNF induces Lif expression via the p38 MAPK pathway in Muller cells in vitro. To determine whether Lif expression is similarly regulated in the healthy or injured neuronal retina in vivo, we injected TNF, a water-soluble p38 MAPK inhibitor (SB220025 trihydrochloride), ${ }^{40}$ or a combination of both into the vitreous of wild-type mice that were or were not exposed to damaging levels of white light (Figures 4-7).
Similar to our observations in cultured Muller cells, TNF injections increased the expression of Lif and Tnf in the retina within $1-2 \mathrm{~h}$ before levels gradually decreased again (Figure 4). Since Fgf2, End2 and Stat3 are part of the LIFcontrolled endogenous neuroprotective signaling system, ${ }^{1,12}$ we also analyzed their expression pattern after TNF injections. Expression of all three genes was significantly upregulated and peaked at around $12 \mathrm{~h}$ after injection and thus with a slight delay compared with Lif (Figure 4). Although not directly tested, this suggests that LIF may also be important for Fgf2, End2 and Stat3 expression after TNF injections, as it is in the injured retina. ${ }^{1,12}$ Similarly, expression of Gfap, which has also been shown to depend on LIF signaling, ${ }^{1}$ was upregulated with a similar delay (Figure 4). In contrast, expression of paired box protein-6 (Pax6), Lif receptor (Lifr) and Cntf, genes that may not depend on LIF signaling, was not comparably regulated. Although CNTF 
Lif

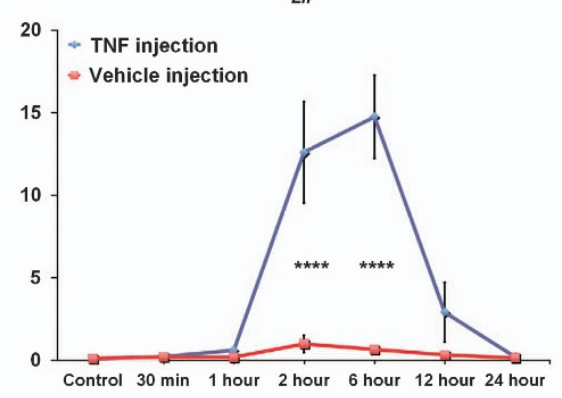

Tnf

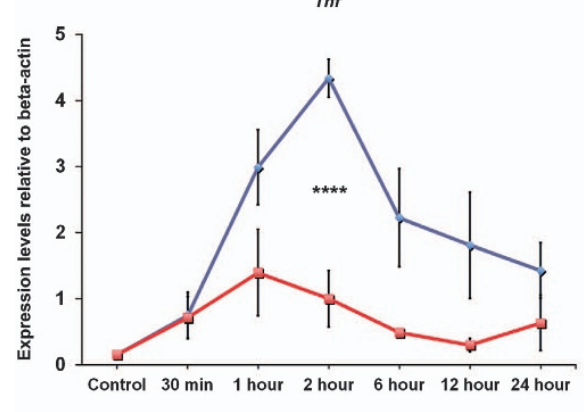

Cntf

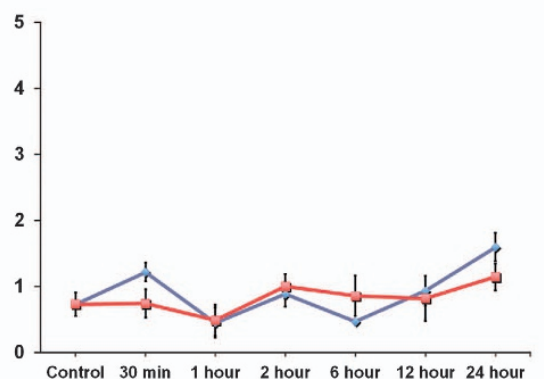

Stat3

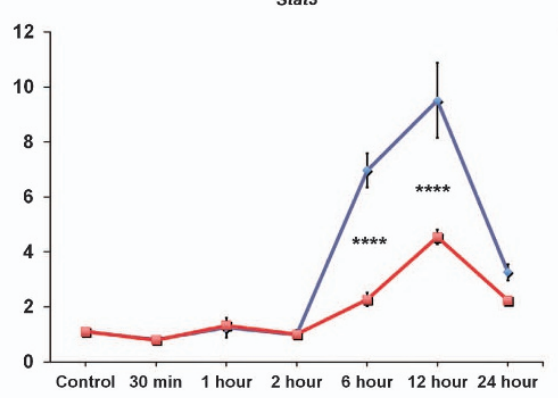

Edn2

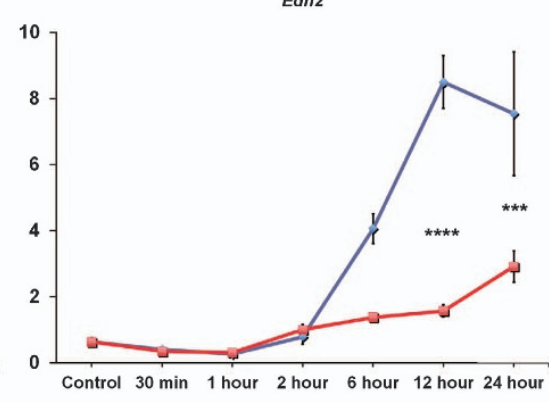

Fgf2

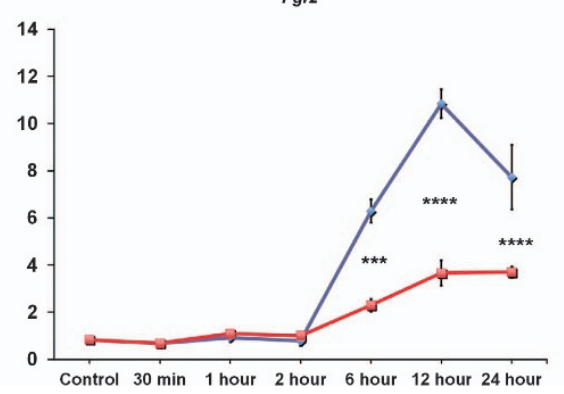

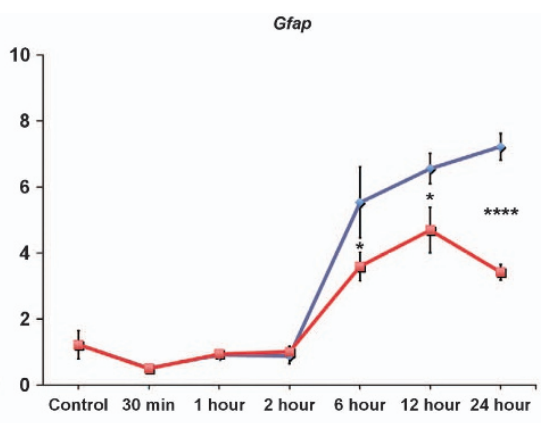

Pax6

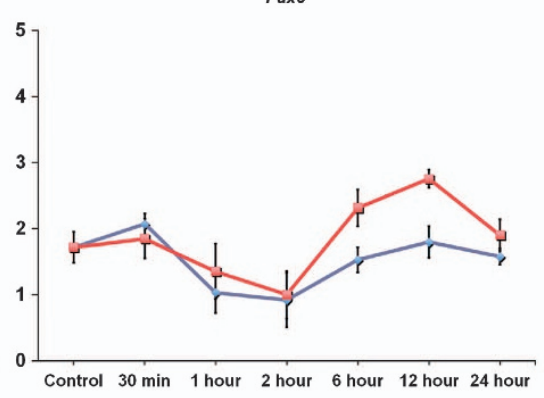

Lifr

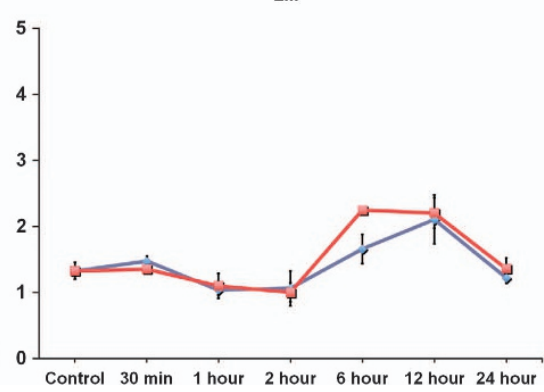

Figure 4 Intravitreal injection of TNF induces Lif gene expression in the neuronal retina in vivo. Real-time PCR analysis of gene expression in retinas of C67BL/6 mice before (control) or at indicated timepoints after intravitreal injection of TNF (blue lines) or vehicle (maroon lines). Lif and Tnf were upregulated as early as $1 \mathrm{~h}$ (Tnf) or $2 \mathrm{~h}$ (Lif) after injection, before levels of Stat3, Edn2, Fgf2 and Gfap started to increase at $6 \mathrm{~h}$. Expression of Cntf, Lifr and Pax 6 was not remarkably affected by the injections. Shown are means \pm S.E.M. of $N=3-4$ per timepoint and treatment. Two-way ANOVA with Bonferroni post-test was used to test for statistical significance between treatments at each timepoint. ${ }^{\star} P<0.05 ;{ }^{\star * *} P<0.005 ;{ }^{\star * \star *} P<0.001$

is strongly neuroprotective in the retina ${ }^{2,3}$ and belongs to the same interleukin-6 (IL-6) family of cytokines as LIF, consequences of TNF injections were thus rather specific for the Lif gene.

To determine whether p38 MAPK is also involved in TNFinduced $L$ if expression in the retina in vivo, we analyzed gene expression at 2 and $6 \mathrm{~h}$ after intravitreal injection of TNF and/or the p38 MAPK inhibitor SB220025. As expected, injection of TNF caused increased Lif RNA levels at both timepoints (Figure 5a). However, when SB220025 was co-injected with TNF, upregulation of Lif expression was reduced by 78 and $73 \%$ at the 2 and $6 \mathrm{~h}$ timepoints, respectively. Injection of vehicle or SB220025 alone slightly upregulated Lif expression probably due to injection-inflicted retinal injury (Figure 5a). Western blots of retinal extracts showed an approximately 7.5-fold increase in phosphorylation levels of p38 MAPK at $2 \mathrm{~h}$ after TNF injection as compared with controls, suggesting that TNF increases p38 MAPK activity in the retina (Figures $5 b$ and c). Injection of the p38 MAPK inhibitor (which does not block phosphorylation but the activity of $\mathrm{p} 38 \mathrm{MAPK})^{40}$ either alone or in combination with TNF also resulted in increased p38 phosphorylation levels which may suggest an attempt of inhibitor-treated retinal cells to increase p38 MAPK activity by a positive feedback. Since vehicle injections upregulated phospho-p38 MAPK levels by 3.5-fold, intravitreal injections per se may generate a stress response and activate $\mathrm{p} 38 \mathrm{MAPK}$ to a certain degree (Figures $5 \mathrm{~b}$ and $\mathrm{c}$ ). In summary, these data imply that the p38 MAPK pathway is also important for TNF-mediated Lif regulation in the neuronal retina in vivo.

p38 MAPK is an important regulator for increased Lif expression after exposure to damaging light in vivo. We showed that TNF-induced Lif upregulation depends on p38 MAPK activity in the healthy wild-type retina. To test whether Lif regulation depends on p38 MAPK also in a disease model, we exposed dark-adapted mice to high-intensity white light that has been shown to cause photoreceptor degeneration and to upregulate Lif expression in Muller cells. ${ }^{1}$ Six hours after light exposure, Lif levels were increased 62-fold 
a

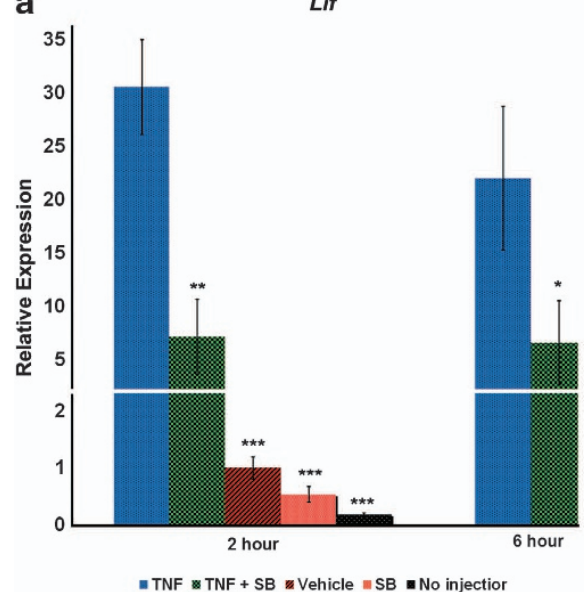

b
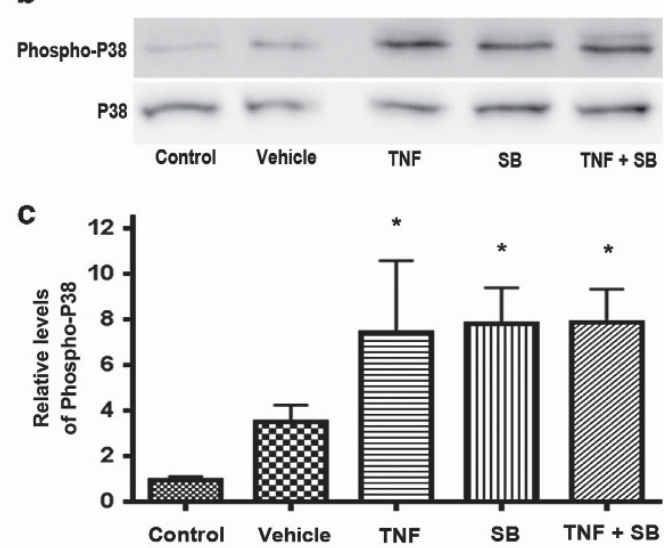

Figure 5 Activation of p38 MAPK is essential for TNF-induced upregulation of Lif expression in the neuronal retina in vivo. (a) RT PCR analysis of gene expression in retinas of C67BL/6 mice before (no injection, black bars) or at 2 and $6 \mathrm{~h}$ after intravitreal injection of TNF (blue bars), p38 MAPK inhibitor SB220025 (SB, pink bar), TNF + p38 MAPK inhibitor SB220025 (TNF + SB, green bar) or vehicle (maroon bar). TNF-mediated upregulation of Lif expression was significantly attenuated by the p38 MAPK inhibitor. Shown are means \pm S.E.M. of $N=3-4$ per timepoint and treatment. ANOVA with Bonferroni post-tests was used to compare expression levels after TNF injection with levels of remaining groups at the 2 -h timepoint. Student's $t$-test was used to compare expression at $6 \mathrm{~h} .{ }^{*} P<0.05 ;{ }^{* *} P<0.01 ;{ }^{* * \star} P<0.005$. (b) Detection of phospho-p38 MAPK (upper panel) and p38 MAPK (lower panel) by western blot of protein extracts from retinas before (control) or at $2 \mathrm{~h}$ after injection of vehicle, TNF, p38 MAPK inhibitor SB220025 (SB), or TNF + p38 MAPK inhibitor SB220025 (TNF + SB) as indicated. Injection of TNF, SB and TNF + SB increased levels of phospho-p38 MAPK compared with vehicle and uninjected retinas. Shown are representative blots. (c) Quantification of signals detected by western blot in (b) using Bio1D software. Phospho-p38 MAPK levels were highest after injection of TNF, of p38 MAPK inhibitor SB220025 (SB) and of TNF + p38 MAPK inhibitor SB220025 (TNF + SB). Shown are means \pm S.E.M. of $N=3-9$ per treatment. ANOVA with Bonferroni post-tests was used to compare levels to control. ${ }^{*} P<0.05$

(Figure 6). Intravitreal injection of vehicle immediately after light exposure slightly further increased Lif levels. Importantly, however, injection of p38 MAPK inhibitor SB220025 reduced Lif levels by $57 \%$ compared with vehicle injections. Similarly to observations made before (Figure 5a), vehicle injection induced Lif expression also in non-exposed mice (dark controls). As in the light-exposed retinas, injection of SB220025 reduced this induction by about 63\% (Figure 6).

SB-mediated inhibition of Lif expression in the lightexposed retina was not as strong as in TNF + SB-injected retinas (Figure 5a), most probably because the SB inhibitor was injected for experimental reasons $2 \mathrm{~h}$ after the start of light exposure and thus only after the Lif-inducing signaling cascade had been activated by the light stimulus. Cardiotrophin-like cytokine $(C / c)$ is another member of the IL-6 family of cytokines that is upregulated in response to light damage. ${ }^{12}$ Similarly to Lif, induction of $\mathrm{Cl} c$ was partially inhibited by SB treatment (Figure 6). Analysis of Cntf, Gfap and vimentin (Vim), which are expressed in Muller cells, ${ }^{41-43}$ did not show any significant changes as a result of SB treatment (Figure 6). These results imply that p38 MAPK is involved in controlling Lif upregulation after light-induced photoreceptor injury in vivo.

p38 MAPK activity is neuroprotective in the model of light-induced photoreceptor degeneration. If p38 MAPK is indeed important for regulation of neuroprotective Lif in the injured retina, inhibition of its activity should increase photoreceptor damage after light exposure. To directly test this hypothesis, we quantified cell death in the retina at $40 \mathrm{~h}$ after exposure of wild-type mice to high levels of white light. Although intravitreal injections had a protective effect in general (vehicle), inhibition of p38 MAPK by SB220025 significantly increased cell death as compared with vehicle injections (compare 'SB' to 'vehicle'). In contrast, TNF injections reduced cell death almost to dark control levels (Figure 7). Importantly, cell death showed a distinct negative correlation with levels of Lif mRNA after no, SB, vehicle or TNF injections (Figures $5 \mathrm{a}$ and 7 ), corroborating earlier findings that showed that dosage and timing of Lif expression is an important factor for retinal physiology and neuroprotection. ${ }^{13,44,45}$ These results strongly argue that LIF-mediated endogenous neuroprotection after light damage depends on p38 MAPK signaling in the retina.

\section{Discussion}

Regulation of Lif expression in Muller cells. Our results demonstrate that p38 MAPK signaling is required for the regulation of Lif expression in Muller cells in vitro and in the retina in vivo. We also show that inhibition of p38 MAPK activity reduces Lif expression and increases cell death in a model of photoreceptor injury supporting a direct role for p38 MAPK in LIF-mediated neuroprotection in the retina. Furthermore, treatment with recombinant TNF was sufficient to activate p38 MAPK, to increase Lif expression in vitro and in vivo, and to protect against light damage in vivo. However, whether endogenous TNF is involved in regulating Lif expression in the injured retina in vivo needs still to be determined, even though Tnf expression is induced early after light exposure in the eyecup. ${ }^{46}$

p38 MAPK activity has been shown to be one of the most important stress response factors by regulating the expression of several genes through activation of transcription factors such as ATF2, CHOP, CREB and ELK1. ${ }^{22}$ Additionally, p38 MAPK affects gene expression at the 

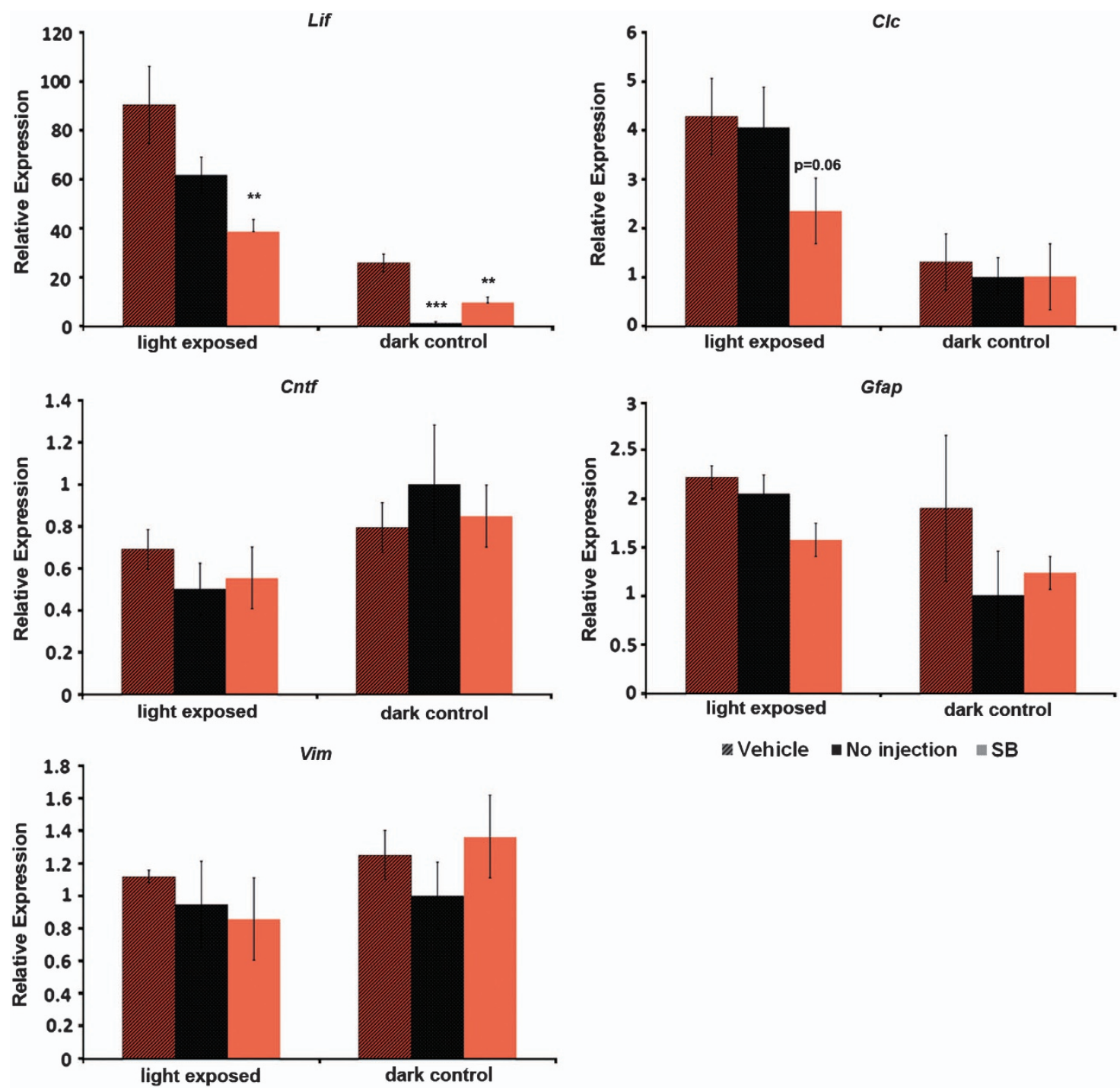

vehicle $\square$ No injection $\because S B$

Figure 6 p38 MAPK is involved in light-induced Lif upregulation in vivo. Real-time PCR analysis of retinal gene expression before (dark controls) or at $6 \mathrm{~h}$ after exposure to $2 \mathrm{~h}$ of 13000 lux of white light. Vehicle (maroon bars) or p38 MAPK inhibitor SB220025 (SB, pink bars) was injected into the vitreous immediately after the end of light exposure. Injections in dark-exposed control mice were done at a similar timepoint during the day to control for potential circadian alterations in gene expression. Light exposure significantly upregulated Lif expression in non-injected (black bars) and vehicle-injected eyes. Upregulation was prevented by SB injections. Note that Lif levels in light-exposed mice after SB injections were not different from dark control mice after vehicle injections. Expression of Clc was regulated similarly to Lif. Levels of Cntf, Vim and Gfap were not affected by light exposure or injections. Shown are means \pm S.E.M. of $N=3-7$ per treatment. ANOVA with Bonferroni post-tests was used to compare levels after vehicle injection to levels after SB injections and to levels of mice that received no injection. Statistics were calculated seperately for the light-exposed groups and the control groups. ${ }^{* \star} P<0.01 ;{ }^{* * \star} P<0.005$

post-transcriptional level by enhancing the stability of target mRNAs containing AU-rich elements in their $3^{\prime}$ UTRs. ${ }^{47}$ In our experimental systems, however, we focused on the effects of p38 MAPK signaling on the regulation of Lif expression at the transcriptional level in vitro and in vivo.

Activation (phosphorylation) of p38 MAPK by TNF was rapid, as was upregulation of Lif expression. The fast upregulation of Lif levels was blocked by an inhibitor of p38 MAPK activity, suggesting that the initial role of p38 MAPK involves transcriptional activation of $L$ if expression. Transcription factors involved in this regulatory pathway have not been defined and their identification will need further investigations. However, $\mathrm{NF} \kappa \mathrm{B}$ is a candidate factor that was upregulated by
TNF treatment in a p38 MAPK-dependent manner (Figure 3), and $\mathrm{NF} \kappa \mathrm{B}$ binding to the Lif promoter has recently been shown in response to TLR2 agonists. ${ }^{39}$ Furthermore, a connection between $\mathrm{p} 38 \mathrm{MAPK}, \mathrm{NF} \kappa \mathrm{B}$ and cytokine regulation has been suggested $^{48}$ and TNF-mediated activation of p38 MAPK is well documented..$^{22}$ Nevertheless, the contribution of $\mathrm{NF} \kappa \mathrm{B}$ to TNF-mediated Lif upregulation may not be major, or else may depend on p38 MAPK. In the presence of TNF and the p38 MAPK inhibitor SB202190, Müller cells retain $50 \%$ of $\mathrm{NF}_{k} \mathrm{~B}$ activity but completely lack Lif upregulation (Figures $3 a$ and $b$ ), at least in vitro.

Regulation of Lif expression may additionally include a second level of complexity. The fast increase in expression 


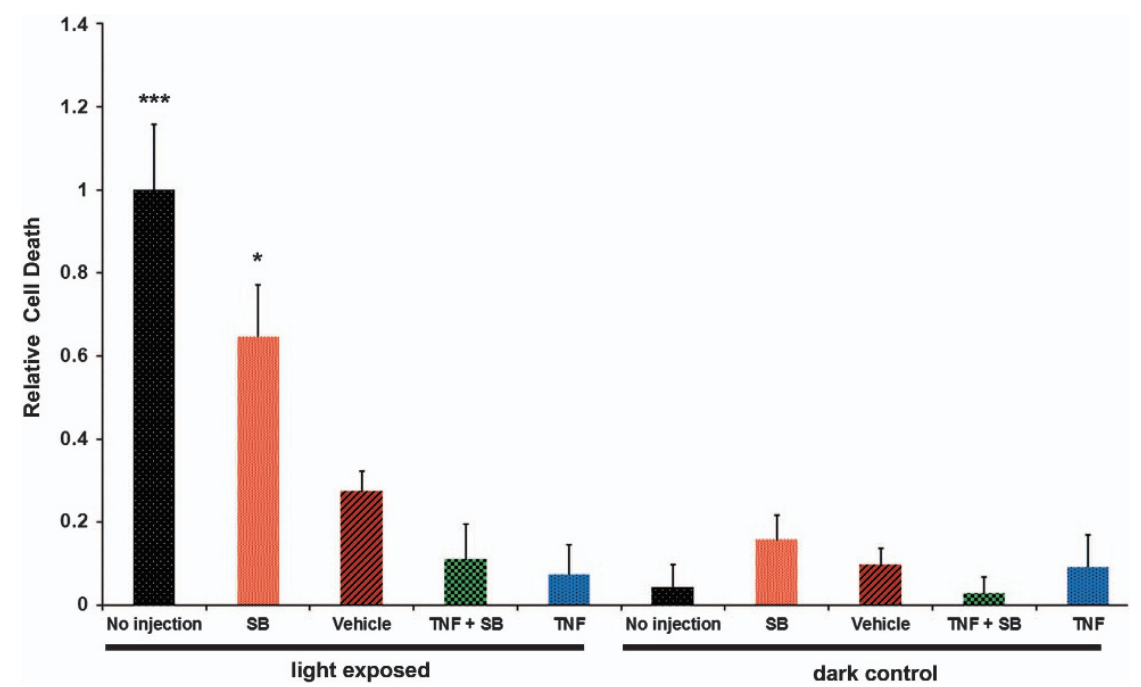

Figure 7 Inhibition of p38 MAPK activity increases cell death in the retina after light exposure in vivo. Quantification of cell death in retinas of non-exposed SV129S6 mice (dark controls) or in retinas of mice at $40 \mathrm{~h}$ after exposure to $2 \mathrm{~h}$ of $13000 \mathrm{lux}$ of white light (light damage). Twenty hours before light exposure, mice received an intravitreal injection of TNF (blue bars), p38 MAPK inhibitor SB220025 (SB, pink bars), TNF + p38 MAPK inhibitor SB220025 (TNF + SB, green bars) or vehicle (maroon bars). No-injection controls (black bars) were treated equally but did not receive intravitreal injections. The highest level of retinal cell death after light exposure was observed in non injected mice. Vehicle injections induced a protection, which was further strengthened by injection of TNF. p38 MAPK inhibitor SB220025 increased cell death almost to the level of non-injected control mice. Shown are means \pm S.E.M. of $N=3-7$ per treatment. ANOVA with Bonferroni post-tests was used to compare levels of cell death of the various groups to vehicle control. Statistics were calculated seperately for the light damage and the dark control group. ${ }^{*} P<0.05 ;{ }^{* * *} P<0.005$

after TNF treatment in vitro (Figure 1) or after light exposure in vivo, ${ }^{11}$ was followed by a rapid decline of Lif mRNA levels towards basal levels. This argues for the presence of a regulatory feedback loop and that transcriptional activation of Lif expression might be followed by transcriptional inhibition or by a reduction of Lif mRNA stability, or both.

Neuroprotective role of p38 MAPK activity and Lif expression. Depending on the concept and experimental setup, activation of p38 MAPK has been shown to promote cell survival or apoptosis. Whereas inhibition of p38 MAPK activity has been reported to protect $661 \mathrm{~W}$ photoreceptor cells against light damage in vitro, ${ }^{49}$ our results indicate that inhibition of p38 MAPK activity accelerates light damage in vivo. This discrepancy may be due to the lack of intercellular communication between photoreceptors, RPE and Muller cells in the in vitro cell culture system. Photoreceptor degeneration induced in vivo by high levels of white light depends on RPE65 in the RPE and on the regeneration kinetics of the bleached chromophore in the visual cycle. ${ }^{50,51}$ Hence mechanisms of light-induced death in isolated $661 \mathrm{~W}$ cells in vitro and photoreceptors in vivo differ and the two experimental systems cannot be directly compared. Of additional importance, photoreceptors injured by light or other stimuli signal to Muller cells, which induce expression of Lif to ignite a neuroprotective response in the retina leading to increased photoreceptor survival. ${ }^{1,8}$ This intercellular communication is not possible in the cell culture system, and effects of p38 MAPK inhibition in $661 \mathrm{~W}$ cells may thus not accurately reflect the in vivo situation where p38 MAPK activity seems important in Muller cells to upregulate expression of neuroprotective Lif.

Despite the neuroprotective role of p38 MAPK, inhibition of its activity in the presence of TNF was still protective against
LIRD, in contrast to inhibitor injections alone (Figure 7). Protection correlated with increased levels of Lif in retinas of eyes injected with a combination of TNF and inhibitor, and with decreased Lif levels after injection of the p38 MAPK inhibitor alone (Figure 5a). This suggests that injection of the p38 MAPK inhibitor was not sufficient to completely block the strong Lifinducing activity of TNF and raises the possibility that a mechanism for TNF-induced Lif upregulation in addition to p38 MAPK may be present in vivo. Alternatively, TNF may potentially have protective effects through other mechanisms such as $\mathrm{NF}_{\kappa} \mathrm{B}$ activation and its downstream targets, or the regulation of heat shock proteins. ${ }^{52}$ It is interesting to note that p38 MAPK inhibitors only partially blocked TNF-induced NF $\kappa$ B activation whereas they completely abolished Lif induction, at least in vitro (Figure 5). This may argue that TNF could regulate the fate of photoreceptor cells via several mechanisms.

Due to the inhibition of pro-inflammatory gene expression, inhibitors of p38 MAPK are discussed as potential therapeutic agents in inflammatory diseases like psoriasis and rheumatoid arthriis. ${ }^{53}$ Moreover, p38 MAPK inhibitors were shown to block tumor growth and metastases formation. ${ }^{54}$ However, our results demonstrating that inhibition of p38 MAPK activity may be detrimental to injured photoreceptor cells ask for precautions when developing p38 MAPK inhibitors for therapeutic use. In cases of open or hidden retinal disease conditions, application of p38 MAPK inhibitors to patients may have adverse effects on vision due to its negative effect on Lif expression and LIF-dependent survival factors in the retina. Similar adverse effects may possibly be observed in other neurodegenerative diseases where LIF has a reported protective activity. ${ }^{55-57}$ Thus, as a safety measure, p38 MAPK inhibitors may be designed not to cross retina-blood or brain-blood barriers, which may prevent potential neurodegenerative effects. 
TNF signaling in the retina. Although most reports attribute TNF a devastating role in the retina and retinal diseases through the modulation of an inflammatory response, ${ }^{28,29}$ our results demonstrate that intravitreal injection of TNF before light exposure did not accelerate degeneration. Rather, TNF reduced the relative average cell death by almost fourfold (0.27 \pm 0.049 S.E.M., $N=6$ for vehicle versus $0.074 \pm 0.07$ S.E.M. for TNF, $N=5$ ). Even though these values did not reach statistical significance when tested in context of the additional experimental paradigms using analysis of variance (ANOVA), they showed a tendency for TNF-mediated protection of photoreceptors against light-induced degeneration (Figure 7). At least part of this effect may be explained by increased expression of Lif which leads to the upregulation of neuroprotective factors like Fgf2, End2 and Stat3 (Figure 4). ${ }^{1,12}$

Emerging evidence indicates that TNF may be a signaling molecule of general importance that has differential effects on disease outcome depending on the interaction with its receptors. In a retinal ischemia-reperfusion model, TNF-R2 signaling was neuroprotective whereas TNF-R1 increased neuronal death. ${ }^{58}$ Moreover, a recent report suggests that TNF expression in dying photoreceptors and Muller cells is important for Muller cell proliferation and photoreceptor regeneration in a zebrafish model of LIRD. ${ }^{19,59}$ Although the mammalian retina diverges from zebrafish in several ways including its limited proliferation and regeneration capacity of Muller cells, ${ }^{60,61}$ these results together with our findings may nevertheless indicate a possible role of TNF for the protection of function in the stressed or injured mammalian retina. Clearly, further studies are warranted to elucidate the role of TNF signaling during photoreceptor degeneration in detail.

\section{Materials and Methods \\ Animals. All experimental protocols were accepted by the Veterinary Authorities of Zurich and experiments were conducted in accordance with the statement of 'The Association for Research in Vision and Ophthalmology' for the use of animals in research. All mice had access to food and water ad libitum and were housed in a light-dark cycle of $12: 12 \mathrm{~h}$ with 60 lux at cage level. All experimental conditions and time points were tested with a minimum of $N=3$ mice. All experimental mice were on a C57BL/6 background except for the light damage experiments in which mice of the SV129/S6 strain were used (Figure 7). For intravitreal injections after light exposure Rlbp::GFP mice ${ }^{62}$ on a C57BL/6 background were used (Figure 6).}

\section{Cell culture assays}

TNF and p38 MAPK inhibitor treatment. rMC-1 cells ${ }^{36}$ were cultured in Dulbecco's modified Eagle's medium (Life Technologies, Grand Island, NY, USA) supplemented with $10 \%$ fetal bovine serum (Life Technologies), $100 \mathrm{U} / \mathrm{ml}$ penicillin and $100 \mu \mathrm{g} / \mathrm{ml}$ streptomycin (Life Technologies), and grown in a humidified $5 \%$ $\mathrm{CO}_{2}$ incubator as described in Sarthy et al. ${ }^{36}$ Rat recombinant TNF (R\&D Systems, Minneapolis, MN, USA) was dissolved in PBS containing $0.1 \%$ bovine serum albumin (BSA) (Sigma Aldrich, St Louis, MO, USA), the p38 MAPK inhibitors SB202190 and SB239063 (Sigma Aldrich) were dissolved in water or in DMSO (Sigma Aldrich), respectively. Compounds were added alone or in combinations directly to growth media at concentrations and times indicated in the Results section.

Luciferase assay. rMC-1 cells were transfected using FuGENE6 reagent (Promega, Madison, WI, USA). Renilla luciferase expressing vector, pRL-CMV (Promega), was used as an internal control to normalize the transfection efficiency. Transfection solution was prepared in $91 \mu \mathrm{l}$ Optimem (Life Technologies) media using $3 \mu \mathrm{g} / \mathrm{ml}$ of total plasmid DNA and $9 \mu$ l of FuGENE6 reagent according to manufacturer's instructions. The ratio of renilla to firefly plasmids was 1:9. Ten thousand cells in $100 \mu \mathrm{l}$ growth media were seeded on a 96-well plate and each well was transfected with $3.3 \mu \mathrm{l}$ of transfection solution after attachment. An EGFP reporter vector, EGFP-C1 (Clontech, Mountain View, CA, USA), was used to assess the transfection efficiency of rMC-1 cells, which was between 15 and $20 \%$. Cells were transfected either with a control vector, pTAL-luc (Clontech), or with an NF $\kappa$ B reporter vector, pNF $\kappa$ B-luc (Clontech). TNF, SB202190 and TNF + SB202190 treatments were performed for $6 \mathrm{~h}$ starting at $24 \mathrm{~h}$ after transfection. TNF and SB202190 had final concentrations of $10 \mathrm{ng} / \mathrm{ml}$ and $100 \mu \mathrm{M}$, respectively. Each treatment was performed in triplicates in four independent experiments. Luciferase levels were measured using the Dual Luciferase kit (Promega).

Immunoblotting. Protein homogenates were prepared by sonication (Branson sonifier, 10 strokes of $0.3 \mathrm{~s}$ with $30 \%$ output) of isolated retinas in Tris- $\mathrm{HCl}$ $(100 \mathrm{mM}, \mathrm{pH} 7.5 \mathrm{or} \mathrm{pH} 8.0)$. Protein concentrations were determined by Bradford using BSA as standard. Homogenates were mixed with an equal volume of $4 \mathrm{X}$ Laemmli sample buffer and a total of $40 \mu \mathrm{g} / \mathrm{ml}$ protein was loaded in each lane of $10 \%$ SDS-polyacrylamide gels. Samples were electrophoresed, blotted and probed as described previously in Bürgi et al. ${ }^{12}$ To detect phospho-p38 MAPK (cat no. 840771; R\&D Systems) and p38 MAPK (cat no. 9212; Cell Signaling, Danvers, MA, USA) primary antibodies were used at a dilution of 1:500 and 1:1000, respectively. The secondary antibody, anti-rabbit lgG peroxidase-linked (cat no. NA934; GE Healthcare, Pittsburgh, PA, USA), was used at a dilution of 1:10000. We have used WesternBright Sirius HRP substrate (Advansta, Menlo Park, CA, USA) for chemiluminescence reaction. Fusion FX7 Advance imaging system (Vilber Lourmat, Torcy, France) with a CCD camera was used for digital signal detection. Recordings were taken at the dynamic range of exposure without binning. Calculations for exposure levels were performed using BioD1 software (Vilber Lourmat) without background subtractions.

RT-PCR analysis. Retinas were collected through a slit in the cornea, and total RNA was prepared and analyzed by real-time PCR (RT-PCR) as described previously in Bürgi et al. ${ }^{12}$ Briefly, $10 \mathrm{ng}$ cDNA was amplified in a LightCycler instrument (Roche Diagnostics, Basel, Switzerland) using appropriate primer pairs (Table 1) and SybrGreen Master mix (Roche). Actb was used as reference gene. For the analysis of gene expression in rMC-1 cells, total RNA was extracted using the Megamax RNA isolation kit (Life Technologies) according to manufacturer's instructions. cDNA was prepared using the high-capacity CDNA reverse transcription kit (Life Technologies). Real-time PCR reactions were conducted using appropriate primer pairs (Table 1) and Actb as internal control. Additional internal controls, Gapdh and Rpl32, were used for each new treatment. Real-time PCR reactions were performed in a StepOne Real-Time PCR system with Fast SybrGreen master mix (Life Technologies). The comparative cycle threshold method was used to calculate relative transcript levels for both mouse and rat experiments.

Intravitreal injections. Intravitreal injections were performed as previously described in Joly et al. ${ }^{1}$ Rat recombinant TNF (R\&D Systems) was reconstituted in sterile PBS containing $0.1 \%$ BSA (Sigma Aldrich) and injected at a concentration of $10 \mu \mathrm{g} / \mathrm{ml}$. SB220025 trihydrochloride (Sigma Aldrich) was dissolved in water and adjusted to $6 \mathrm{mM}$ using sterile PBS containing $0.1 \%$ BSA for injections. Sterile PBS containing $0.1 \%$ BSA was used for vehicle control injections. For the injection of TNF + SB220025, stock solutions for SB220025 and TNF were mixed and diluted with PBS containing $0.1 \%$ BSA to reach final injection concentrations of $10 \mu \mathrm{g} / \mathrm{ml} / \mathrm{ml}$ and $6 \mathrm{mM}$ for TNF and SB220025, respectively. Injection volume was $1 \mu \mathrm{l}$.

Light damage and cell death assay. Light damage and quantification of cell death by an ELISA-based cell death assay (Roche Diagnostics, Basel, Switzerland) were performed essentially as previously described in Bürgi et al. ${ }^{12}$ and Samardzjia et al. ${ }^{10}$ with minor modifications. White light intensity for light damage was set to 13000 lux, and 6-10-week-old animals with dilated pupils ${ }^{12}$ were exposed for $2 \mathrm{~h}$. Animals were kept in darkness overnight before and after light exposure. Animals were sacrificed and retinas were isolated for cell death assay at $40 \mathrm{~h}$ after light exposure.

Data analysis. Statistical analysis was performed using ANOVA with Dunnett's Multiple Comparison tests where multiple comparisons were made to a single value. ANOVA with Bonferroni post-test was performed for multiple 
Table 1 Real-time PCR primer sequences

\begin{tabular}{|c|c|c|c|}
\hline Gene & Species & Forward primer & Reverse primer \\
\hline Cntf & $\mathrm{Rn}$ & CTCTGTAGCCGTTCTATCTG & GGTACACCATCCACTGAGTC ${ }^{\mathrm{Rn} / \mathrm{Mm}}$ \\
\hline Fgf2 & $\mathrm{Rn}$ & GGCTGCTGGCTTCTAAGTGT & TCCGTGACCGGTAAGTGTTG \\
\hline Gapdh & $\mathrm{Rn}$ & ATGACTCTACCCACGGCAAG & GGAAGATGGTGATGGGTTTC \\
\hline Gfap & $\mathrm{Rn}$ & AGTGGTATCGGTCCAAGTTTGC & TGGCGGCGATAGTCATTAGC \\
\hline Lif & $\mathrm{Rn}$ & ATGAAGGTCTTGGCCACAGG & GTATGGCGCAGGTGGCATT \\
\hline Tnf & $\mathrm{Rn}$ & CCACGCTCTTCTGTCTACTGA RN/MM & GGCCATGGAACTGATGAGAGG \\
\hline$R p / 32^{21}$ & $\mathrm{Rn}$ & AAGCGAAACTGGCGGAAAC & TAACCGATGTTGGGCATCAG \\
\hline Actb & $\mathrm{Rn} / \mathrm{Mm}$ & CAACGGCTCCGGCATGTGC ${ }^{\mathrm{Rn} / \mathrm{Mm}}$ & CTCTTGCTCTGGGCCTCG ${ }^{R n / M m}$ \\
\hline Clc & $\mathrm{Mm}$ & CCCTGGCCCCTCCATCCAGAAA & TGCCCCCAGTCGAGGAGGATTG \\
\hline Cntf & $\mathrm{Mm}$ & CTCTGTAGCCGCTCTATCTG & GGTACACCATCCACTGAGTC ${ }^{\mathrm{Rn} / \mathrm{Mm}}$ \\
\hline Edn2 & $\mathrm{Mm}$ & AGACCTCCTCCGAAAGCTG & CTGGCTGTAGCTGGCAAAG \\
\hline Fgf2 & $\mathrm{Mm}$ & TGTGTCTATCAAGGGAGTGTGTGC & ACCAACTGGAGTATTTCCGTGACCG \\
\hline Gapdh & $\mathrm{Mm}$ & CAGCAATGCATCCTGCACC & TGGACTGTGGTCATGAGCCC \\
\hline Gfap & $\mathrm{Mm}$ & CCACCAAACTGGCTGATGTCTAC & TTCTCTCCAAATCCACACGAGC \\
\hline Lif & $\mathrm{Mm}$ & AATGCCACCTGTGCCATACG & CAACTTGGTCTTCTCTGTCCCG \\
\hline Lifr & $\mathrm{Mm}$ & ACTGAAGTGGAACGACAGAGG & CTTTACCACTCAGCATTGTGTTG \\
\hline Pax6 & $\mathrm{Mm}$ & AGTTCTTCGCAACCTGGCTA & CATCTGAGCTTCATCCGAGT \\
\hline Stat3 & $\mathrm{Mm}$ & CAAAACCCTCAAGAGCCAAGG & TCACTCACAATGCTTCTCCGC \\
\hline Tnf & $\mathrm{Mm}$ & CCACGCTCTTCTGTCTACTGA ${ }^{\mathrm{Rn} / \mathrm{Mm}}$ & CCACGCTCTTCTGTCTACTGA \\
\hline Vim & $\mathrm{Mm}$ & TACAGGAAGCTGCTGGAAGG & TGGGTGTCAACCAGAGGAA \\
\hline
\end{tabular}

Rn, Rattus norvegicus; Mm, Mus musculus

Primers used for both rat and mouse samples are marked (Rn/Mm)

comparisons against independent controls. Student's t-tests were used for individual pairwise comparisons. $P$-values lower than 0.05 were considered to be significant. Error bars represent the standard error of the mean (S.E.M.). We also used the ROUT algorithm, with the coefficient $Q$ value of 0.1 , to detect possible outliers related to intravitreal injections. Graph Pad 6 software or Prism 5 (GraphPad Inc., San Diego, CA, USA) were used for all statistical analyses.

\section{Conflict of Interest}

The authors declare no conflict of interest.

Acknowledgements. We thank Dr. Vijay Sarthy (Northwestern University, Chicago, IL, USA) for providing rMC-1 cells. We also thank the members of the Institute of Laboratory Animal Science, University Hospital Zurich, for support in animal care. We wish to thank Swiss National Science Foundation and Velux Foundation for financial support to $C G$ and $C A$. $C A$ and $C G$ designed the experiments. $\mathrm{CA}, \mathrm{AG}, \mathrm{GT}, \mathrm{CB}, \mathrm{Cl}, \mathrm{DA}, \mathrm{CC}$ and $\mathrm{CG}$ performed the experiments. $\mathrm{CA}$ and $C G$ wrote the manuscript.

1. Joly S, Lange C, Thiersch M, Samardzija M, Grimm C. Leukemia inhibitory factor extends the lifespan of injured photoreceptors in vivo. J Neurosci 2008; 28: 13765-13774.

2. Leibinger M, Muller A, Andreadaki A, Hauk TG, Kirsch M, Fischer D. Neuroprotective and axon growth-promoting effects following inflammatory stimulation on mature retinal ganglion cells in mice depend on ciliary neurotrophic factor and leukemia inhibitory factor. J Neurosci 2009; 29: 14334-14341.

3. Azadi S, Johnson LE, Paquet-Durand F, Perez MT, Zhang Y, Ekstrom PA et al. CNTF + BDNF treatment and neuroprotective pathways in the rd1 mouse retina. Brain Res 2007; 1129: 116-129.

4. Campochiaro PA, Nguyen QD, Shah SM, Klein ML, Holz E, Frank RN et al. Adenoviral vector-delivered pigment epithelium-derived factor for neovascular age-related macular degeneration: results of a phase I clinical trial. Hum Gene Ther 2006; 17: 167-176.

5. Frigg R, Wenzel A, Grimm C, Reme CE. [Survival factors in the treatment of hereditary retinal degeneration]. Ophthalmologe 2005; 102: 757-763.

6. Grimm C, Wenzel A, Groszer M, Mayser H, Seeliger M, Samardzija M et al. HIF-1-induced erythropoietin in the hypoxic retina protects against light-induced retinal degeneration. Nat Med 2002; 8: 718-724.

7. Sahel JA. Saving cone cells in hereditary rod diseases: a possible role for rod-derived cone viability factor (RdCVF) therapy. Retina 2005; 25(8 Suppl): S38-S39.

8. Rattner A, Nathans J. The genomic response to retinal disease and injury: evidence for endothelin signaling from photoreceptors to glia. J Neurosci 2005; 25: 4540-4549.

9. Schaeferhoff K, Michalakis S, Tanimoto N, Fischer MD, Becirovic E, Beck SC et al. Induction of STAT3-related genes in fast degenerating cone photoreceptors of cpfl1 mice. Cell Mol Life Sci 2010; 67: 3173-3186.
10. Samardzija M, Wariwoda H, Imsand C, Huber P, Heynen SR, Gubler A et al. Activation of survival pathways in the degenerating retina of rd10 mice. Exp Eye Res 2012; 99: 17-26.

11. Samardzija M, Wenzel A, Aufenberg S, Thiersch M, Reme C, Grimm C. Differential role of Jak-STAT signaling in retinal degenerations. FASEB J 2006; 20: 2411-2413.

12. Burgi S, Samardzija M, Grimm C. Endogenous leukemia inhibitory factor protects photoreceptor cells against light-induced degeneration. Mol Vis 2009; 15: 1631-1637.

13. Ueki Y, Wang J, Chollangi S, Ash JD. STAT3 activation in photoreceptors by leukemia inhibitory factor is associated with protection from light damage. J Neurochem 2008; 105 : 784-796.

14. Chollangi S, Wang J, Martin A, Quinn J, Ash JD. Preconditioning-induced protection from oxidative injury is mediated by leukemia inhibitory factor receptor (LIFR) and its ligands in the retina. Neurobiol Dis 2009; 34: 535-544.

15. Groeger G, Mackey AM, Pettigrew CA, Bhatt L, Cotter TG. Stress-induced activation of Nox contributes to cell survival signalling via production of hydrogen peroxide. $J$ Neurochem 2009; 109: 1544-1554.

16. Bhatt L, Groeger G, McDermott K, Cotter TG. Rod and cone photoreceptor cells produce ROS in response to stress in a live retinal explant system. Mol Vis 2010; 16: 283-293.

17. Mackey AM, Sanvicens N, Groeger G, Doonan F, Wallace D, Cotter TG. Redox survival signalling in retina-derived 661W cells. Cell Death Differ 2008; 15: 1291-1303.

18. Groeger G, Quiney C, Cotter TG. Hydrogen peroxide as a cell-survival signaling molecule. Antioxid Redox Signal 2009; 11: 2655-2671.

19. Nelson CM, Ackerman KM, O'Hayer P, Bailey TJ, Gorsuch RA, Hyde DR. Tumor necrosis factor-alpha is produced by dying retinal neurons and is required for muller glia proliferation during zebrafish retinal regeneration. J Neurosci 2013; 33: 6524-6539.

20. Lorenzo JA, Jastrzebski SL, Kalinowski JF, Downie E, Korn JH. Tumor necrosis factor alpha stimulates production of leukemia inhibitory factor in human dermal fibroblast cultures. Clinical Immunol Immunopathol 1994; 70: 260-265.

21. Hao S, Baltimore $D$. The stability of mRNA influences the temporal order of the induction of genes encoding inflammatory molecules. Nature Immunol 2009; 10: 281-288.

22. Wajant $\mathrm{H}$, Pfizenmaier K, Scheurich $\mathrm{P}$. Tumor necrosis factor signaling. Cell Death Differ 2003; 10: 45-65.

23. Figiel I. Pro-inflammatory cytokine TNF-alpha as a neuroprotective agent in the brain. Acta Neurobiol Exp 2008; 68: 526-534

24. Dolga AM, Granic I, Blank T, Knaus HG, Spiess J, Luiten PG et al. TNF-alpha-mediates neuroprotection against glutamate-induced excitotoxicity via NF-kappaB-dependent up-regulation of K2.2 channels. J Neurochem 2008; 107: 1158-1167.

25. Saha RN, Liu X, Pahan K. Up-regulation of BDNF in astrocytes by TNF-alpha: a case for the neuroprotective role of cytokine. J Neuroimmune Pharmacol 2006; 1: 212-222.

26. Tamatani M, Che YH, Matsuzaki H, Ogawa S, Okado H, Miyake S et al. Tumor necrosis factor induces $\mathrm{Bcl}-2$ and $\mathrm{Bcl}-\mathrm{x}$ expression through NFkappaB activation in primary hippocampal neurons. J Biol Chem 1999; 274: 8531-8538.

27. Viemann D, Goebeler M, Schmid S, Klimmek K, Sorg C, Ludwig S et al. Transcriptional profiling of IKK2/NF-kappa B- and p38 MAP kinase-dependent gene expression in TNF-alpha-stimulated primary human endothelial cells. Blood 2004; 103: 3365-3373.

28. Nakazawa T, Nakazawa C, Matsubara A, Noda K, Hisatomi T, She H et al. Tumor necrosis factor-alpha mediates oligodendrocyte death and delayed retinal ganglion cell loss in a mouse model of glaucoma. J Neurosci 2006; 26: 12633-12641. 
29. Roh M, Zhang Y, Murakami Y, Thanos A, Lee SC, Vavvas DG et al. Etanercept, a widely used inhibitor of tumor necrosis factor-alpha (TNF-alpha), prevents retinal ganglion cell loss in a rat model of glaucoma. PLoS One 2012; 7: e40065.

30. Tezel G, Li LY, Patil RV, Wax MB. TNF-alpha and TNF-alpha receptor-1 in the retina of normal and glaucomatous eyes. Invest Ophthalmol Vis Sci 2001; 42: 1787-1794.

31. Diem R, Meyer R, Weishaupt JH, Bahr M. Reduction of potassium currents and phosphatidylinositol 3-kinase-dependent AKT phosphorylation by tumor necrosis factor-(alpha) rescues axotomized retinal ganglion cells from retrograde cell death in vivo. J Neurosci 2001; 21: 2058-2066.

32. Roth S, Shaikh AR, Hennelly MM, Li Q, Bindokas V, Graham CE. Mitogen-activated protein kinases and retinal ischemia. Invest Ophthalmol Vis Sci 2003; 44: 5383-5395.

33. Kikuchi M, Tenneti L, Lipton SA. Role of p38 mitogen-activated protein kinase in axotomyinduced apoptosis of rat retinal ganglion cells. J Neurosci 2000; 20: 5037-5044.

34. Dreixler JC, Barone FC, Shaikh AR, Du E, Roth S. Mitogen-activated protein kinase p38alpha and retinal ischemic preconditioning. Exp Eye Res 2009; 89: 782-790.

35. Jiang SY, Zou YY, Wang JT. p38 mitogen-activated protein kinase-induced nuclear factor kappa-light-chain-enhancer of activated $B$ cell activity is required for neuroprotection in retinal ischemia/reperfusion injury. Mol Vis 2012; 18: 2096-2106.

36. Sarthy VP, Brodjian SJ, Dutt K, Kennedy BN, French RP, Crabb JW. Establishment and characterization of a retinal Muller cell line. Invest Ophthalmol Vis Sci 1998; 39: 212-216.

37. Underwood DC, Osborn RR, Kotzer CJ, Adams JL, Lee JC, Webb EF et al. SB 239063, a potent p38 MAP kinase inhibitor, reduces inflammatory cytokine production, airways eosinophil infiltration, and persistence. J Pharmacol Exp Ther 2000; 293: $281-288$

38. Fox T, Coll JT, Xie X, Ford PJ, Germann UA, Porter MD et al. A single amino acid substitution makes ERK2 susceptible to pyridinyl imidazole inhibitors of p38 MAP kinase. Protein Sci 1998; 7: 2249-2255.

39. Wang J, Zhang J, Ash JD. Leukemia inhibitory factor expression can be induced by agonist of TLR-2 or gp130, and may require NFkB or STAT3 binding to promoter elements. ARVO 2013; abstract 3251.

40. Jackson JR, Bolognese B, Hillegass L, Kassis S, Adams J, Griswold DE et al. Pharmacological effects of SB 220025, a selective inhibitor of P38 mitogen-activated protein kinase, in angiogenesis and chronic inflammatory disease models. J Pharmacol Exp Ther 1998; 284: 687-692.

41. Bignami $A$, Dahl $D$. The radial glia of Muller in the rat retina and their response to injury. An immunofluorescence study with antibodies to the glial fibrillary acidic (GFA) protein. Exp Eye Res 1979; 28: 63-69.

42. Kivela T, Tarkkanen A, Virtanen I. Intermediate filaments in the human retina and retinoblastoma. An immunohistochemical study of vimentin, glial fibrillary acidic protein, and neurofilaments. Invest Ophthalmol Vis Sci 1986; 27: 1075-1084.

43. Ju WK, Lee MY, Hofmann HD, Kirsch M, Chun MH. Expression of CNTF in Muller cells of the rat retina after pressure-induced ischemia. Neuroreport 1999; 10: 419-422.

44. Graham DR, Overbeek PA, Ash JD. Leukemia inhibitory factor blocks expression of Crx and $\mathrm{Nrl}$ transcription factors to inhibit photoreceptor differentiation. Invest Ophthalmol Vis Sci 2005; 46: 2601-2610.

45. Ash J, McLeod DS, Lutty GA. Transgenic expression of leukemia inhibitory factor (LIF) blocks normal vascular development but not pathological neovascularization in the eye. Mol Vis 2005; 11: 298-308.

46. Joly S, Francke M, Ulbricht E, Beck S, Seeliger M, Hirrlinger $P$ et al. Cooperative phagocytes: resident microglia and bone marrow immigrants remove dead photoreceptors in retinal lesions. Am J Pathol 2009; 174: 2310-2323.
47. Dean JL, Sully G, Clark AR, Saklatvala J. The involvement of AU-rich element-binding proteins in p38 mitogen-activated protein kinase pathway-mediated mRNA stabilisation. Cell Signal 2004; 16: 1113-1121.

48. Craig R, Larkin A, Mingo AM, Thuerauf DJ, Andrews C, McDonough PM et al. p38 MAPK and NF-kappa B collaborate to induce interleukin- 6 gene expression and release. Evidence for a cytoprotective autocrine signaling pathway in a cardiac myocyte model system. J Biol Chem 2000; 275: 23814-23824

49. Yang LP, Zhu XA, Tso MO. Role of NF-kappaB and MAPKs in light-induced photoreceptor apoptosis. Invest Ophthalmol Vis Sci 2007; 48: 4766-4776.

50. Grimm C, Wenzel A, Hafezi F, Yu S, Redmond TM, Reme CE. Protection of Rpe65deficient mice identifies rhodopsin as a mediator of light-induced retinal degeneration Nature Genet 2000; 25: 63-66.

51. Wenzel A, Reme CE, Williams TP, Hafezi F, Grimm C. The Rpe65 Leu450Met variation increases retinal resistance against light-induced degeneration by slowing rhodopsin regeneration. J Neurosci 2001; 21: 53-58.

52. Tezel G. TNF-alpha signaling in glaucomatous neurodegeneration. Prog Brain Res 2008; 173: 409-421.

53. Cohen P. Targeting protein kinases for the development of anti-inflammatory drugs. Curr Opin Cell Biol 2009; 21: 317-324.

54. Marengo B, De Ciucis CG, Ricciarelli R, Furfaro AL, Colla R, Canepa E et al. p38MAPK inhibition: a new combined approach to reduce neuroblastoma resistance under etoposide treatment. Cell Death Dis 2013; 4: e589.

55. Zigmond RE. gp130 cytokines are positive signals triggering changes in gene expression and axon outgrowth in peripheral neurons following injury. Front Mol Neurosci 2011; 4: 62

56. Bauer S, Rasika S, Han J, Mauduit C, Raccurt M, Morel G et al. Leukemia inhibitory facto is a key signal for injury-induced neurogenesis in the adult mouse olfactory epithelium. J Neurosci 2003; 23: 1792-1803.

57. Cheema SS, Richards L, Murphy M, Bartlett PF. Leukemia inhibitory factor prevents the death of axotomised sensory neurons in the dorsal root ganglia of the neonatal rat. J Neurosci Res 1994; 37: 213-218.

58. Fontaine V, Mohand-Said S, Hanoteau N, Fuchs C, Pfizenmaier K, Eisel U. Neurodegenerative and neuroprotective effects of tumor Necrosis factor (TNF) in retinal ischemia: opposite roles of TNF receptor 1 and TNF receptor 2. J Neurosci 2002; 22: RC216.

59. Thomas JL, Nelson CM, Luo X, Hyde DR, Thummel R. Characterization of multiple light damage paradigms reveals regional differences in photoreceptor loss. Exp Eye Res 2012; 97: 105-116.

60. Yurco $\mathrm{P}$, Cameron DA. Responses of Muller glia to retinal injury in adult zebrafish. Vis Res 2005; 45: 991-1002

61. Ooto S, Akagi T, Kageyama R, Akita J, Mandai M, Honda $Y$ et al. Potential for neural regeneration after neurotoxic injury in the adult mammalian retina. Proc Natl Acad Sci USA 2004; 101: 13654-13659.

62. Vazquez-Chona FR, Clark AM, Levine EM. Rlbp1 promoter drives robust Muller glial GFP expression in transgenic mice. Invest Ophthalmol Vis Sci 2009; 50: 3996-4003.

(i) $(5)$ Cell Death and Disease is an open-access journal published by Nature Publishing Group. This work is licensed under a Creative Commons Attribution-NonCommercialNoDerivs 3.0 Unported License. To view a copy of this license, visit http://creativecommons.org/licenses/by-nc-nd/3.0/ 